geget (2019) Volume 14 - Issue1

Original Article

\title{
Screening for Urine Abnormalities Among School Children in Qalubyia
}

\author{
Abd El-Hameed A. Abd El-Hameed', Wesam E. Afifi', Walid A.Abd El-Halim², Maha A. Mohammed ${ }^{3}$ \\ 1- Pediatric Nephrology Department, Faculty of Medicine, Benha University, Egypt \\ 2- Clinical and Chemical Pathology Department, Faculty of Medicine, Benha University, Egypt \\ 3- Benha Children Hospital, Ministry of Health, Egypt
}

\begin{abstract}
Background

Early identification of kidney diseases in children and adolescents is an important initial step in prevention of chronic kidney diseases (CKD). The current study was undertaken to screen asymptomatic school children in Qalubyia governate, Egypt, and to detect the prevalence of renal disorders using urine dipstick method.
\end{abstract}

\section{Aim of Work}

The purpose of the study was to determine the prevalence of urinary abnormalities by dipstick test (reagent strips) in asymptomatic school children.

\section{Patients and Method}

This cross sectional study, was carried out in Qalubyia Governorate, from September 2018 to February 2019. It comprised (1000) school children of both sexes after obtaining an informed consent from the children's care givers. Ages of the children included in the study ranged from 6 to 12 years and they were 411 males $(41.1 \%)$ and 589 females $(58.9 \%)$.

\section{Results}

Out of total 1000 children, 411 (41.1\%) were male children and remaining 589 (58.9\%) were female students. During the first screening by urine dipstick method, $66(6.6 \%)$ children were found to having urinary abnormalities which were further investigated by confirmatory complete urine analysis. Finally 33 were diagnosed having urinary abnormalities. The prevalence rate of isolated hematuria (IH) was $0.9 \%$; isolated proteinuria (IP) was $0.4 \%$; combined hematuria and proteinuria (CHP) was $0.1 \%$ and urinary tract infection (UTI) was $1.8 \%$ and Glycosuria was $0.1 \%$. In microscopic urine examination, crystals was found positive in $0.8 \%$ of the cases. Abnormality in sonography of kidneys were found in 5 cases. Urine culture results were positive in 8 cases.

\section{Conclusions}

In conclusion, asymptomatic urinary abnormalities might be detected by urine screening program at school age.

\section{Keywords}

Urinary Dipstick Screening, School Children, and Renal Diseases.

\section{Correspondence}

Maha A. Mohammed

Benha Children Hospital, Ministry of Health, Egyp

Email: maha.abdelaty89@gmail.com

\author{
geget : The Journal of the Egyptian Society of Pediatric Nephrology and Transplantation (ESPNT) \\ geget https://geget.journals.ekb.eg/ \\ Published by ESPNT http://espnt.net/ \\ Cohosted by Egyptian Knowledge Bank https://www.ekb.eg
}




\section{Introduction}

Chronic kidney disease (CKD) is a global public health problem; its incidence is steadily increasing among children [1]. Egypt is similar to other developing countries in that there is no current national epidemiologic data on pediatric chronic renal failure (CRF) and its risks [2]. Detection and management of renal problems in children are of major importance for CKD prevention; this in turn will decrease the burden of CKD in the pediatric population [3]. Screening for asymptomatic urinary abnormalities (AUA) is useful for early detection of renal diseases and asymptomatic infections, particularly among children [4].

Urine analysis is recognized as the simplest and least expensive method for screening healthy children [5].

The basic dipstick method is the most rapid screening procedure that could be helpful in the early detection of renal or urinary tract diseases among apparently healthy or asymptomatic subjects in the hope of preventing and retarding progression to chronic renal failure [6].

Proteinuria and hematuria are among the early manifestations of renal disease [7]. The presence of a dipstick test $1+$ or $\geq 2+$ for proteinuria was strongly associated with renal risk [8]. Also, the presence of detectable nitrites in urine has been used to diagnose urinary tract infection [6].

Mass screening helps to design population oriented preventive measures that will limit the need for dialysis and transplantation [9]. Prevention is more important in our setting given the shortage of financial resources and the fact that dialysis centers, equipment, and trained personnel are simply not available to the general population. Hence, this study was planned [10].

\section{Aim of the work}

This study was done to determine the prevalence of urinary abnormalities by using dipstick test among apparently healthy school children living in Qalubyia governorate.

\section{Subjects and Methods}

All children enrolled in this study were subjected to full history taking, and clinical examination. Morning urine specimen obtained from each student was tested with urine dipstick for protein, blood, glucose, nitrite and leukocyte (urine quick test; Combur-10-Test ${ }^{\mathrm{TM}}$, Roche, Mannheim, Germany). A dipstick test was performed on the urine specimen with reagent strip designed to react and progressively produce color changes in 30 seconds. The results were obtained by visual comparison of the test strip with a color chart provided on the bottle label.

Students with an initial reading of $\geq 1+$ for any abnormalities were subjected to complete urine examination. A red blood cell count of five or more per high power field (HPF), one or more plus protein, one or more plus glucose, pus cells count of ten or more per high power field (HPF) and crystals were considered as abnormal urine findings [11].

\section{Statistical analysis}

Statistical analysis was done by using statistical package for social science (SPSS). Qualitative data were expressed in the form of numbers and percentages. Comparison between data was performed by using the Chi-square test. A $\mathrm{P}$ value less than 0.05 was considered statistically significant.

\section{Results}

This cross sectional study, was carried out in Qalubyia Governorate, from

September 2018 to February 2019. It comprised (1000) school children of both sexes after obtaining an informed consent from the children's care givers. Ages of the children included in the study ranged from 6 to 12 years and they were 411 males $(41.1 \%)$ and 589 females $(58.9 \%)$.

Table 1: Urinary Abnormalities Found in Children $(\mathrm{n}=1000)$.

\begin{tabular}{|c|c|c|c|c|c|}
\hline & Cases & Percentage & Cases & Percentage & P Value \\
\hline Hematuria & 27 & $2.7 \%$ & 9 & $0.9 \%$ & $<0.001$ \\
\hline Proteinuria & 10 & $1 \%$ & 4 & $0.4 \%$ & $<0.05$ \\
\hline Mixed hematuria and proteinuria & 3 & $0.3 \%$ & 1 & $0.1 \%$ & $>0.05$ \\
\hline Glucose & 1 & $0.1 \%$ & 1 & $0.1 \%$ & $>0.05$ \\
\hline Leucocyte & 25 & $2.5 \%$ & 18 & $1.8 \%$ & $<0.001$ \\
\hline
\end{tabular}

This table shows that there was significant difference between the dipstick test results and the microscopic urine analysis results as regard hematuria, proteinuria and leucocytes but no significant difference as regard mixed hematuria and

proteinuria. 
Table 2: Comparison between positive and negative groups according to age, and sex.

\begin{tabular}{|c|c|c|c|c|c|}
\hline \multicolumn{2}{|c|}{} & Negative (n=968) & Positive (n=32) & Test of sig. & p-value \\
\hline \multicolumn{2}{|c|}{ Age (mean \pm SD) } & $8.90 \pm 2$ & $8.84 \pm 2.1$ & t=1.149 & $>0.05$ \\
\hline $\begin{array}{c}\text { Sex } \\
\text { No. }(\%)\end{array}$ & Girls & $569(58.7)$ & $20(62.5)$ & \multirow{2}{*}{$\mathrm{X}^{2}=0.17$} & $>0.05$ \\
\cline { 2 - 5 }
\end{tabular}

This table shows that there is no statistically significant difference between positive and normal children according to age and sex $(\mathrm{p}>0.05)$.

Table 3: Comparison between boys and girls with persistent urinary abnormalities as regards clinical data (Age, weight, height, SBP and DBP).

\begin{tabular}{|c|c|c|c|c|c|c|}
\hline & \multicolumn{2}{|c|}{ Female $(n=20)$} & \multicolumn{2}{|c|}{ Male $(n=12)$} & \multirow{2}{*}{$\mathbf{t}$} & \multirow{2}{*}{ p-value } \\
\hline & Mean & Std. Deviation & Mean & Std. Deviation & & \\
\hline Age in years & 9.45 & 2.13 & 7.83 & 1.7 & 2.2 & \\
\hline Systolic BP & 99 & 11.5 & 95.8 & 10.6 & 0.773 & \\
\hline Diastolic BP & 65.75 & 6.7 & 63.75 & 7.4 & 0.782 & \\
\hline WT in kg & 36.2 & 9.7 & 27.83 & 9.06 & 2.41 & \\
\hline Height in cm & 132.95 & 10.77 & 123.08 & 8.36 & 2.71 & \\
\hline
\end{tabular}

This table shows that there was no significant difference between boys and girls as regard SBP and DBP. But there is significant difference as regard age, weight, and height more in female. 
Table 4: The results of urine culture.

\begin{tabular}{|c|c|c|}
\hline Organism & Cases & Percentage \\
\hline E.coli & 2 & $11.1 \%$ \\
\hline Klebsiellia & 3 & $16.7 \%$ \\
\hline Pseudomonas & 1 & $5.6 \%$ \\
\hline Staphaureus & 2 & $11.1 \%$ \\
\hline No growth & 10 & $55.6 \%$ \\
\hline Total & $\mathbf{1 8}$ & $\mathbf{1 0 0 \%}$ \\
\hline
\end{tabular}

This table shows that the urine culture was performed to 18 children (with pus cells in microscopic urine analysis $>20$ WBCs/hpf) and it was positive in 8 cases (one boy and 7 girls). The commonest organism detected is Klebsiellia then E.coli and Staphaureus followed by Pseudomonas.

Table 5: Sex distribution among cases of positive urine culture.

\begin{tabular}{|c|c|c|c|}
\hline Sex & No. & Percentage & P value \\
\hline Boys & 1 & $87.5 \%$ & $<0.001$ \\
\hline Girls & 7 & $\mathbf{1 0 0 \%}$ & \\
\hline
\end{tabular}

This table shows that there was highly significant difference between boys and girls as regard positive urine culture as girls more affected than boys.

Table 6: Results of Abdominal Sonography in some selected cases with hematuria as a final diagnosis.

\begin{tabular}{|c|c|c|}
\hline & Cases & Percentage \\
\hline Normal & 4 & $44.4 \%$ \\
\hline Cystitis & 3 & $33.3 \%$ \\
\hline Left renal stone & 2 & $22.2 \%$ \\
\hline Total & 9 & $100.0 \%$ \\
\hline
\end{tabular}

This table shows that the abdominal ultrasound was performed to 9 students with isolated hematuria to exclude renal stones or any congenital abnormalities. Four students showed normal ultrasound, 5 students showed abnormal ultrasound as 3 cases suggestive to cystitis, 2 cases showed left renal stone. 
Table 7: Distribution of positive crystals cases according to its type.

\begin{tabular}{|c|c|c|}
\hline Crystals & No. & \multicolumn{2}{|c|}{ \%.8 } \\
\hline Amorphous urate & 3 & 3.2 \\
\hline Ca-oxalate & 2 & 3.2 \\
\hline Uric acid & 2 & 1.6 \\
\hline Phosphate & 1 & 13 \\
\hline Total positive & 8 & 87 \\
\hline Negative & 58 & 100 \\
\hline Total positive\& negative & 66 & \\
\hline
\end{tabular}

This table shows that 8 students (13\% from positive 66 children) were positive for different types of crystals. Three were positive for amorphous urate, two were positive for Ca-oxalate and uric acid, one was positive for phosphate.

\section{Discussion}

To reduce the number of patients with both end stage renal diseases (ESRD) and cardiovascular diseases, effective screening and treatment methods for chronic kidney disease (CKD) should be established [12]. Screening the general population may decrease the incidence of ESRD resulting from glomerulonephritis [13]. Urinary tract infection (UTI) in children is a relatively common diagnosis encountered in general pediatric practice. Because of the potential severity of such infections, the workup is an important part of management. Protocols for evaluation of any urinary tract abnormalities, appropriate management is essential [14].

In our study the prevalence of urinary abnormalities detected by Dipstick test was (6.6\%), which was similar to the study done by [15] in china who reported that the urinary abnormalities were detected in $(7.1 \%)$ of his studied cases, also [16] in Shiraz (Iran) reported (4.7\%) of urinary abnormalities in his studied cases. A lower prevalence was reported in [17] in Lebanon who reported $(2.9 \%)$ of his cases and in [18] in Yazd (Iran) who reported $(3.1 \%)$ of his studied cases. On the contrary a higher prevalence has been reported in those of [19] in Assuit Governorate who reported (13.5\%) and [20] who reported $(25.1 \%)$ in Saudi Arabia.

Our study shows that the prevalence of isolated hematuria by the dipstick was (2.7\%) similarly to [17] in Lebanon which was (2\%). It was higher than those of [21] in Vietnam who reported a prevalence of $(0.1 \%)$ and [18] in Yazd (Iran) who reported a prevalence of $(1.5 \%)$. In contrast, a higher prevalence has been reported in [19] study in Assuit Governorate which was (8.9\%) and in [20] in Saudi Arabia which was (17\%). Our study revealed that the prevalence of isolated hematuria was higher than the prevalence of isolated proteinuria. It is in agreement with [17] and [20] and disagrees with those of [22] in Nigeria and [18] in Yazd (Iran) who concluded that the prevalence of isolated proteinuria was higher than isolated hematuria.

In our study Dipstick-detected proteinuria was encountered in (1\%) of our cases. This was in agreement with study done by [18] who reported $(1.7 \%)$ of his cases presented with proteinuria, our results were higher than that was reported by [20] who reported $(0.5 \%)$ and that reported by [17] in Lebanon who reported $(0.2 \%)$ and lower than that was reported by [19] study in Assuit Governorate who reported $(3.5 \%)$ of his cases. Among Indian school children a ratio of $16 \%$ of studied cases showed proteinuria on their random urine samples [23]. This may be due to screening large number of students in this study. Proteinuria in a single urine specimen is relatively common in children with a reported prevalence of $1-10 \%$, while persistent proteinuria is much less common [24]. Congenital structural abnormalities and tubular disorders occur more commonly in children than in adults and are characterized by significant excretion of low molecular weight proteins that would not be detected by testing exclusively for albumin. Proteinuria is considered a strong independent risk factor of end stage renal disease. Thus, asymptomatic proteinuria warrants attention for early detection and management [25].

In our study combined hematuria and proteinuria was found in $(0.3 \%)$ of our positive dipstick cases. It is in agreement with other studies done by [22], [26], and [19] whom reported $(0.2 \%),(0.2 \%)$ and $(0.6 \%)$ respectively. However, [18] didn't detect any cases of combined hematuria and proteinuria. The difference in the prevalence of isolated hematuria, isolated proteinuria and combined hematuria and proteinuria may be explained by sociodemographic characters or geographic causes. 
In our study dipstick-detected glycosuria was encountered in $(0.1 \%)$. It is in agreement with [20] and [19] whom reported $(0.6 \%)$ and $(0.3 \%)$ respectively. And disagree with [17] who reported no cases of glycosuria. In our study the prevalence of leucocytoria in the dipstick test was $(2.5 \%)$. This is lower than [20] who reported (14.3\%) and higher than [18] who reported $(0.3 \%)$. On the other hand, [19] and [17] show no cases of leucocytoria. Of our studied cases $(3.3 \%)$ showed urinary abnormalities in their microscopic urine examination. [19] Reported (2.3\%), [18] reported $(0.6 \%)$ and [26] in Dakahlia reported $(0.72 \%)$. This may be due to the increased prevalence of pyuria and crystalluria in our result which were not included in other studies.

In our study the prevalence of hematuria by complete urine examination was $(0.9 \%)$ which agrees with the study of [19] who reported a prevalence of $(1.69 \%)$ of his cases and lower than the study of [20] who reported a prevalence of $(2.5 \%)$ of his cases. This was higher than study done by [26] reported a prevalence of $(0.36 \%)$ of his cases. With repeated evaluations, the prevalence of asymptomatic microscopic hematuria decreases to less than $0.5 \%$, supporting the notion that most cases of hematuria in children are transient [27]. In our study, complete urine examination shows that isolated proteinuria was found in $(0.4 \%)$ of our cases, which agrees with [18] who reported $(0.3 \%)$, and disagrees with [19] who didn't detect any proteinuria in microscopic urine analysis.

The prevalence of combined hematuria and proteinuria in our study was $(0.1 \%)$ which agree with [26] who reported $(0.2 \%)$ and [18] who reported $(0.06 \%)$. In our study the prevalence of glucosuria was $(0.1 \%)$ which agrees with [19] who reported $(0.2 \%)$. In our study pyuria was detected in $(1.8 \%)$ of our studied cases. it was lower than those of [20] who reported (5\%), and higher than those of [19] who reported (1\%).

In our study the mean age was found to be lower among children with positive results compared to normal children. The difference was statistically non-significant. Our study agrees with those of [26] who concluded that there was no significant difference in the prevalence of urinary abnormalities among the studies students with referral to their age, and disagree with those of [19] in Assuit who reported that the prevalence was higher in older children. The study by [17] showed that most urinary abnormalities were detected as six years of age.

The study revealed that there is significant difference in the prevalence of urinary abnormalities between the studied students according to their sex, it agrees with other studies as those of [22] in Nigeria, [17] in Lebanon, [18] in Yazad (Iran) and [21] whom reported that the urinary abnormalities were more common among girls than boys. In contrast, [28] showed that microscopic urinary abnormalities were more common in males than females. The higher incidence of urinary tract infection in the girls is attributed to the fact that girls have short urethra which predispose them to ascending bacterial infection [22].

In our study there was significant difference between the dipstick test results and the microscopic urine analysis results. This agrees with all previously mentioned studies. This can be explained by that most cases of hematuria and $\backslash$ or proteinuria in children are transient and hence the importance of microscopic urine analysis test in detecting the real prevalence of these abnormalities. The differences between prevalence of dipstick and microscopic urine analysis can be explained also by the possibility of false positive results of dipstick being a good negative and not good positive test.

In our study there was no statistically significant difference found between boys and girls as regards their clinical data (HR, SAR, and ABP) which agrees with the study of [19]. Our study shows the prevalence of crystalluria was $(0.8 \%)$, it agrees with the study of [19].

In our study urine culture was performed to 18 students with pyuria, it was positive in 8 students only. The causative organisms were klebsiella in the urine of 3 students, staphaureus in 2 students, E.Coli in 2 students and Pseudomonas in one student. [20] in Saudi Arabia performed urine culture to 50 cases with pyuria, it was positive in 20 cases, the causative organisms were E.Coli in 15 cases and Enterococcin in 5 cases, also in [19] urine culture was performed to 13 students with pyuria and it was positive in all of them. The causative organisms were staphaureus in 4 cases and E.Coli in 9 cases.

In our study there is statistically significant difference between the affected cases as regard sex as the number of males affected was only one and the number of females was 7 females. This difference between both sexes can be explained by the anatomical difference in urethra between boys and girls as short urethra in girls lead to increased risk to infection and high rate of recurrences.

In our study abdominal ultrasound was performed to 9 cases or isolated hematuria to exclude renal stones or any congenital abnormalities. 4 students showed normal ultrasound, 5 students showed abnormal ultrasound as 3 cases suggestive to cystitis and 2 cases showed left renal stones. In [19] abdominal ultrasound was done to all students with isolated hematuria and showed normal finding. However study done by [21] in Vietnam, abdominal ultrasound was done to cases with isolated hematuria, it was abnormal in 5 cases. Four cases showed hydronephrosis and duplication of ureter in one case.

\section{Conclusion}

The prevalence of urinary abnormality among the studied students detected by complete urine examination was $(3.2 \%)$. screening urine analysis among Egyptian school children for prediction of asymptomatic urinary abnormalities is an important step in early detection and management of any renal disorder. Screening tests by dipstick followed by microscopic urine analysis for persistent abnormalities is a convenient and acceptable work up for early detection of renal disorders. 


\section{References}

1- Gulati S, Finberg L, \& Windle ML: Chronic Kidney Disease in Children. 2018. URL:https://emedicine.medscape.com/article/984358.

2- Kari JA: Pediatric renal diseases in the Kingdom of Saudi Arabia. World J Pediatr 2012; 8: 217-221.

3- Parakh P, Bhatta NK, Mishra OP, et al.: Urinary screening for detection of renal abnormalities in asymptomatic school children. Nephrol Mon 2012; 4:551-555.

4- Mohamed O. Nour, Ali E. Mansour, Ahmed A. Ghandour, et al.: Prevalence of Asymptomatic Urinary Abnormalities among Primary School Children in Damietta Governorate. Umm Al-Qura Univ.

Medical J. 2013; 4(1): 1-8.

5- Abdulla A. Alharthi, Azza A. Taha, Awatif E. Edrees, et al.: (Screening for urine abnormalities among preschool children in western Saudi Arabia.

Saudi Med J 2014; 35: 1477-1481.

6- El-Abden MY, Abo-ElKheir OI, El-Sadek SM, et al.: Screening of renal diseases by urine analysis in primary school aged children at El-Gharbiya governorate-Egypt. Egypt J Hosp Med. 2013; 50:24-33.

7- Akor F, Okolo S, Agaba E, et al.: Urine examination findings in apparently healthy new school entrants in Jos, Nigeria. South African J of Child Health; 2009, 3: 60-63.

8- Gansevoort RT, Bakker SJL, and de Jong PE: Early detection of progressive chronic kidney disease: is it feasible? J Am Soc Nephrol; 2006, 17: 1218-1220.

9- Koduru Srinivasulu, K. Vara Prasada Rao, and K. Praveen Kumar): Urine Analysis as a Screening Tool in Early Detection of Renal Abnormalities in Asymptomatic School Children. World J Nephrol Urol. 2018; 7(1):17-24. 10- Vinoth, B Vignesh Kumar, and Betty Chacko: Screening for Asymptomatic Renal Disease among School Children from Chennai City, India. International Journal of Scientific Study. 2015; 3(7): 207-211.

11- Abdel Basset A, Sarhan A, Hammed A, Ragab M et al.: Urinary screening abnormalities in asymptomatic primary school Egyptian children. Journal of Pediatr Club, (2005), 5 (2):55-58.

12- Levey AS, Eckardt KU, Tsukamoto Y, Levin A, Price $\mathrm{B}$, Wald JW et al): Definition and classification of chronic kidney disease: A position statement from Kidney Disease: Improving Global Outcomes (KDIGO).

Kidney Int ; 2005 67: 2089- 100.

13- Van D, Velde M, Halbesma N, Bakher SJ, Zeeuw D, Gansevoort RT et al: Screening for albuminuria identifies individuals at increased renal risk. $\mathrm{J}$

Am Soc Nephrol; 2009, 20(4):852-62.

14- Shah L, Mandlik N, Kumar P, Andaya S and Patamasucon P : Adherence to AAP Practice Guidelines for Urinary Tract Infections at Our Teaching Institution. Clin Pediatr; 2008, 47(9); 861-9.

15- Rao J, Zhou LJ, Shen Q et al: School urinalysis screening in Shanghai

World J Pediatric ; 2006, 2 (3):195-198.

16- Shajari H, Fallah MH and Sharjari A: Screening of renal diseases in the first primary school children in Shiraz. Acta Medica Iranica ; 4, 2007, 5: 215-8.

17- Hajar F, Taleb M, Aoun B and Shatila A: Dipstick urine analysis screening among asymptomatic school children. North Am J Med Sci, (2011), 3: 179-184.

18- Abd Al-Hamid Jafari Nodoshan, Ahmad Shajari, Azam Golzar, Mehrdad Shakiba: urinary screening in primary school children in yazd,iran.

Shiraz E-Med J; 1, 2015, 6 (1): e23866.

19- Abd El-Naser M: Urine analysis screening among Egyptian school children for prediction of asymptomatic urinary abnormalities. Thesis submitted for partial fulfillment of master degree in pediatrics in Ain Shames University. 2010, URL: http://www.eulc.edu.eg/

20- Alharthi AA, Taha AA, Edrees AE, Elnawawy AN, Abdelrahman AH: Screening for urine abnormalities among preschool children in western Saudi Arabia. Saudi Med J; 2014, 35: 1477-1481.

21- Dang le NN, Doan Tle B, Doan NH, Pham TK, Smets F, Thi MH et al:Epidemiological urinalysis of children from kindergartens of Can Gio, Ho Chi Minh City Vietnam. BMC Pediatr ; 2013,13: 183.

22- Akor F, Okolo S, Agaba E and Okolo A: Urine examination findings in apparently healthy new school entrants in Jos, Nigeria.

SA J Child Health; 2009, 3 (2): 60-63

23- Patil PM, Hipparagi SB, Sinha KS, Sorangavi VM: Asymptomatic Proteinuria and Hematuria in School Going Children. Journal of Krishna Institute of Medical Sciences University, 2013, 2: 105-108.

24- Steven J: Childhood urinary conditions. Australian family physician; 2005, 34(11): 937-41.

25- El-Tayeb M, El Setouhy M, and El Sayed H, Elshahawy Y: Screening of proteinuria in young adults: Is it worthwhile?

Dialysis \& Transplantation; 2010, 39: 522-526.

26- Bakr A, Sarhan A, Hammad A, Ragab M, Salama OS and Al-Husseni F: Asymptomatic urinary abnormalities among primary school children in Egypt. World J Pediatr; 2007, 3:214-7.

27- Sanjeev G and Deogracias P: Hematuria. Medscape; E medicine, Pediatrics; 2010, 1- 10.

28- Lin CY, Sheng CC, Chen CH, Lin CC, Chou P: The prevalence of heavy proteinuria and progression risk factors in children undergoing urinary screening. Pediatr Nephrol.; 2000, 14(10-11):953-9.

\section{Declaration}

\section{Ethics approval and consent to participate}

This study protocol and the consents were approved and deemed sufficient by Ethical Committee of Pediatric Department, Faculty of Medicine, Benha University. And informed written consent was obtained in every case from their legal guardians.

Funding: The authors declare that they didn't receive any financial support from agencies or others.

Conflict of interest: No

We would like to thank all patients and their family members for their valuable contributions to the study. 